\title{
Distribuição das Rendas do Petróleo e Indicadores de Desenvolvimento Municipal no Brasil nos Anos 2000
}

\author{
Fernando Antonio Slaibe Postali* \\ Marislei Nishijima**
}

\begin{abstract}
Resumo
Em 1997, o governo brasileiro aprovou a Lei 9478/97, que estabelecia novos critérios para a distribuição de royalties do petróleo entre os municípios brasileiros e ampliou as possibilidades de uso desses recursos em áreas sociais. O objetivo deste artigo é investigar empiricamente se os royalties distribuídos sob esta lei contribuíram para a melhoria dos indicadores sociais dos municípios contemplados, em relação à média nacional, no período de 2000 a 2007. Utilizou-se o Índice FIRJAN de Desenvolvimento Social (IFDM) e seus três componentes: IFDM - Educação, IFDM - Saúde e IFDM - Emprego\&Renda, como medida de desenvolvimento social. Os resultados mostram que as rendas do petróleo não produziram impactos significativos nos indicadores sociais de saúde e de educação dos municípios beneficiados, mas, de forma surpreendente, geraram efeitos negativos sobre seus setores formais de trabalho.
\end{abstract}

\section{Palavras-Chave}

rendas do petróleo, royalties, desenvolvimento regional, indicadores sociais

\section{Classificação JEL}

Q32, Q38

\section{Distribution of Oil Rents and Local Development Indicators in Brazil in the $2000^{s}$}

\begin{abstract}
In 1997, the Brazilian government approved the Law 9478/97, which has established new criteria for the distribution of oil royalties among municipalities and expanded the possibilities of using these resources in social areas. The aim of this paper is to investigate empirically whether the royalties distributed under this law contributed to the improvement of social indicators of the municipalities relative to the national average in the period 2000 to 2007. We used the Social Development Index FIRJAN (IFDM) and its three components: IFDM - Education, IFDM - Health and IFDM - Employment \& Income as a measure of social development. The results show that the oil revenues produced no significant impacts on social indicators of health and education of municipalities benefited, but, surprisingly, generated negative effects on their formal sector work.
\end{abstract}

\section{Keywords}

oil rents, royalties, regional development, social indicators

\section{JEL Classification}

Q32, Q38

\footnotetext{
* Artigo recebido em julho de 2009 e aceito para publicação em novembro de 2010.

* Professor Doutor - Departamento de Economia - FEA-USP - Endereço para contato: Av. Professor Luciano Gualberto, 908 - Cidade Universitária - São Paulo-SP - CEP: 05508-010 - Email: postali@usp.br

** Professora Associada EACH-USP - Endereço para contato: Av. Arlindo Béttio, 1000 - Ermelino Matarazzo São Paulo - SP - CEP: 03828-000 - Email: marislei@usp.br
} 


\section{Introdução}

As províncias petrolíferas brasileiras são distribuídas de modo desigual ao longo do território brasileiro. Existem diversos municípios que sofrem impactos negativos das atividades de produção de petróleo e gás, e, com vistas a evitar potenciais perdas de bem-estar nestas localidades (como, por exemplo, degradação ambiental), o Governo Federal proporciona a tais municípios uma compensação financeira através de um percentual das receitas de rendas do petróleo. Em 1997 foi aprovada uma nova Lei (9478/97, também conhecida como Lei do Petróleo), que instituiu o novo marco regulatório deste setor, garantindo parcela expressiva dos recursos de petróleo para diversos municípios brasileiros.

Nesta lógica de compensação, uma das mudanças mais notáveis foi a introdução de novos critérios para o cálculo e para a distribuição destas rendas para os municípios direta ou indiretamente afetados por atividades de produção de petróleo.

A Lei do Petróleo estabelece quatro modalidades básicas pelas quais o governo extrai renda das atividades de produção do petróleo: i) Bônus de Assinatura; ii) Royalties; iii) Participações Especiais e iv) Taxa de Ocupação e Retenção da área.

O Bônus de Assinatura corresponde ao lance vencedor no leilão de licitação conduzido pela Agencia Nacional do Petróleo (ANP), com vistas a alocar direitos de exploração. Deve ser pago integralmente, em parcela única, no ato de assinatura do contrato de concessão.

Os royalties representam a principal forma de participação governamental e constituem um imposto de $10 \%$ sobre o valor bruto da produção mensal de petróleo. Os recursos arrecadados são divididos entre os estados e os municípios produtores (ou que sofrem impactos), o Tesouro Nacional e os Ministérios da Ciência e Tecnologia e da Marinha.

As participações especiais não incidem sobre todos os projetos. Trata-se de compensações extraordinárias ao Governo incidentes somente sobre campos de grande rentabilidade. Este imposto é aplicado a partir de alíquotas progressivas que variam entre $10 \%$ e $40 \%$, de acordo com uma regra complexa que leva em conta a profundidade do campo, a idade e o volume de produção. Os recursos provenientes das participações especiais devem ser distribuídos entre os estados e os municípios produtores e os Ministérios das Minas e Energia e do Meio Ambiente. 
Por fim, a taxa de retenção e ocupação de áreas representa uma espécie de aluguel calculado por km2 de área retida para produção, que deve ser pago ao longo da vigência da concessão.

Conforme salienta Serra (2003), compensações financeiras para estados e municípios são muito anteriores a 1997, mas a Lei 9478 instituiu mudanças importantes: a alíquota de royalties, que subiu de 5\% para 10\%, passou a ser aplicada sobre um preço de referência, ou seja, uma cotação média de preços de uma cesta de tipos de petróleo internacionais. Anteriormente, os royalties eram calculados com base no preço da refinaria, o qual costumava sofrer intervenções discricionárias do governo. Além disso, foram criadas novas regras para a distribuição da parcela da arrecadação que excede $5 \%$, resultando na elevação substancial da participação dos municípios na receita global de royalties.

A Lei 9478 também ampliou o conjunto de possibilidades para o investimento dos royalties por parte dos municípios: a Lei anterior $(7527 / 86)$ autorizava as prefeituras a aplicarem estas receitas somente para investimentos em energia, meio ambiente, saneamento e rodovias. A Lei de 1997 não estabelece nenhum vínculo específico e, conforme o entendimento do Tribunal de Contas do RJ (QUINTELLA, 2000), os royalties podem ser destinados a quaisquer investimentos, vedando-se apenas a destinação de tais recursos para o pagamento de dívidas e para folha de pagamento.

Este conjunto de mudanças resultou em um incremento expressivo no valor dos royalties repassado aos municípios, tornando-o muito mais sensível às oscilações do preço internacional do petróleo e da taxa de câmbio, além de ampliar o escopo de possibilidades para a aplicação destas receitas. As novas regras elevaram a arrecadação de royalties de forma significativa após 1998, assim como a sua distribuição para estados e municípios, conforme se observa no Gráfico 1: 


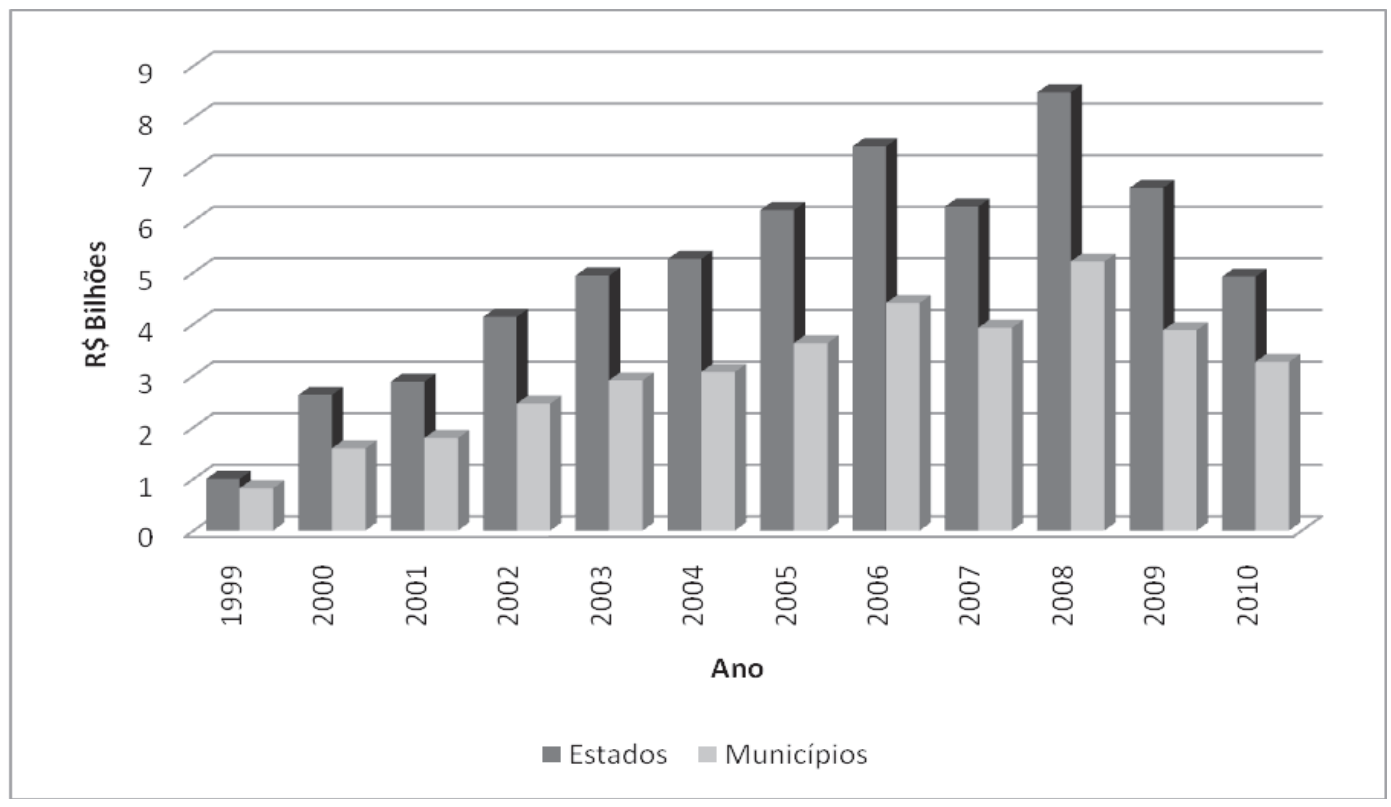

\section{Gráfico 1 - Receitas do Petróleo - Royalties e Participações Especiais Distribuídos a Entes Federativos}

Fonte: Postali (2002), p.20.

Este tema é de grande relevância atualmente no Brasil, pois discussões recentes têm proposto a substituição do atual critério de distribuição de royalties por novas regras que estabeleçam uma distribuição mais equitativa destes recursos para os municípios brasileiros. ${ }^{1}$ Tramita no Congresso Nacional uma proposta que aplica aos royalties do petróleo os mesmos critérios de distribuição do Fundo de Participação dos Municípios (FPM), o que implicaria severas perdas para localidades atualmente beneficiadas. As regras introduzidas em 1997 são controversas, já que concentram os recursos em municípios produtores e/ou afetados por atividades de produção e distribuição. Além disso, a nova fronteira exploratória do pré-sal tem motivado revisões gerais no marco regulatório instituído pela Lei do Petróleo, além de gerar perspectivas de elevação substancial no volume destas receitas nas mãos de estados e municípios. Assim, uma avaliação dos efeitos dos recursos até agora distribuídos é de grande valia para subsidiar o debate.

O objetivo deste artigo consiste em investigar empiricamente, em todo o território nacional, se as rendas do petróleo - notadamente royalties e participações especiais

1 Escolha que difere da lógica da compensação mencionada anteriormente. 
geraram evolução diferenciada nos indicadores sociais dos municípios contemplados ao longo da última década, quando comparados com municípios que não se beneficiaram de tais recursos, isto é, comparados com seu grupo de controle. Como medida de desenvolvimento social, utilizou-se o IFDM, calculado pela Federação das Indústrias do Estado do Rio de Janeiro a partir da compilação de diversos indicadores sociais relativos à educação, saúde, renda e emprego.

Alguns trabalhos têm estudado a relação entre os royalties recebidos por uma localidade e seu grau de desenvolvimento social. A partir de dados da Agência Nacional do Petróleo e do TCE-RJ, Leal e Serra (2002) analisam a aplicação das receitas de royalties em municípios do norte fluminense. Os autores concluem que os municípios contemplados com essas receitas, na forma da nova lei, destinaram recursos para investimentos em volume superior à média do estado, mas o valor deste investimento tem se mostrado sistematicamente menor que o montante de royalties recebido. Costa Nova (2005) analisa diversos indicadores sociais de alguns municípios baianos que receberam valores expressivos de royalties, concluindo que, apesar da relativa folga orçamentária, não aumentaram de forma significativa a qualidade de seus indicadores sociais quando comparados com municípios que não têm direito a estes recursos.

Com relação ao município fluminense de Campos dos Goytacazes - o maior beneficiário de rendas do petróleo, em termos brutos -, Navarro (2003) avaliou que seu IDH evoluiu ligeiramente acima do de cidades similares ao longo da década de 1990. Este município também aumentou seus investimentos em saneamento e em infraestrutura, mas a uma proporção menor que as rendas recebidas de petróleo.

Bregman (2007) é autor de um amplo estudo sobre a aplicação das receitas de royalties pelos municípios beneficiários no Brasil. Seu estudo investigou a relação entre elas e as despesas de capital em municípios dependentes de recursos do petróleo para o período de 1999 a 2005. Suas conclusões apontam que os municípios cujos orçamentos mais dependem de rendas do petróleo investiram proporcionalmente à recepção de tais receitas.

Postali (2009) explorou a Lei 9478/97 para avaliar o impacto das rendas petrolíferas sobre o crescimento econômico dos municípios beneficiados pela nova legislação. As conclusões apontam para uma relação inversa entre receitas de royalties e crescimento do PIB municipal per capita após o ano 2000, momento a partir do qual os recursos do petróleo cresceram substancialmente em função do choque cambial e do aumento do preço do barril. ${ }^{2}$

2 Este fenômeno pode ser interpretado como uma manifestação de certo tipo de "maldição dos recursos naturais", nos moldes de Sachs e Warner (2001). Ver também Davis e Tilton (2005). 
Caselli e Michaels (2009) também elaboram um estudo abrangente acerca dos efeitos dos royalties sobre indicadores sociais de localidades brasileiras - avaliadas por Áreas Mínimas Comparáveis - assim como sobre suas despesas. Quanto ao lado fiscal, os autores concluem que as receitas extraordinárias do petróleo de fato geram algum aumento em despesas ligadas à qualidade social, como infraestrutura urbana, saúde e educação. Por outro lado, os indicadores sociais não responderam satisfatoriamente ao aumento destes recursos.

Este artigo visa contribuir com a discussão a partir da utilização da base de dados da FIRJAN. Além desta introdução, o trabalho possui mais quatro seções: a seção seguinte traz algumas considerações sobre a relação entre bem-estar e rendas de recursos naturais não renováveis, com o intuito de identificar os fundamentos que norteiam a apropriação destas receitas pelo poder público; a seção 3 descreve a metodologia e os dados utilizados, enquanto a seção 4 apresenta os resultados; a seção 5 , por fim, apresenta considerações conclusivas.

\section{Considerações Teóricas entre Recursos Não Renováveis, Rendas e Bem- Estar}

O estudo das especificidades do processo de produção de recursos não renováveis é antigo, levando diversos autores clássicos (como RICARDO, 1817) a refletirem sobre o tema. A peculiaridade fundamental deste tipo de atividade é a limitação física de seu estoque na natureza, implicando a indisponibilidade do recurso para as gerações futuras caso ele seja extraído no presente. Esta característica remete ao conceito de custo de uso, um tipo particular de custo de oportunidade com características temporais: a extração de um recurso não renovável hoje acarreta um custo de oportunidade de extraí-lo em algum momento futuro. O custo de uso é a diferença entre o preço do recurso e seu custo marginal de produção e faz parte da renda que seria, desta forma, uma compensação ao proprietário da jazida pela redução no seu valor devido à extração de seus recursos. Este componente da renda também é denominado renda de Hotelling.

Hotelling (1931) foi o pioneiro na criação de um conceito próprio para as rendas dos recursos minerais. Na sua concepção, a renda dos recursos minerais está ligada ao seu custo de uso. Dados os direitos de propriedade sobre os recursos, o proprietário define a trajetória de extração a partir da maximização do valor da jazida ao longo do tempo. Desta forma, o custo de uso de extrair o recurso no instante atual é a receita de que se abre mão na extração futura, gerando uma renda compensatória para o detentor da propriedade dos recursos. O resultado da análise de Hotelling 
(1931) é que a renda do recurso (custo de uso) deve crescer à taxa de juros com o objetivo de otimizar a trajetória de extração, evitando-se que o produtor arbitre a distribuição da produção ao longo do tempo e prejudique as gerações presentes ou futuras.

Deve-se a Hartwick (1977) uma das contribuições seminais para o entendimento da relação entre a renda de um recurso e o bem-estar da população, identificando as condições que ligam rendas de recursos à sustentabilidade econômica. Considerando o fato estilizado de um país com apenas um recurso não renovável e sem fontes de recursos para investimento, ele demonstrou que mesmo um país nesta situação-limite é capaz de manter um nível de consumo per capita constante indefinidamente, desde que invista certa porção da renda mineral total em capital reprodutível físico e humano. Este resultado ficou conhecido na literatura como Regra de Hartwick.

A intuição subjacente à Regra de Hartwick é a interpretação do recurso não renovável como um ativo cujo valor decresce à medida que o recurso é exaurido. $\mathrm{O}$ valor de qualquer ativo, em equilíbrio, é a soma de seus retornos líquidos futuros descontados. No caso dos recursos exauríveis, tais retornos são seus valores-sombras futuros, descontados (preço menos custo marginal de extração) ou seu custo de uso. A redução no valor do capital quando o recurso é exaurido, correspondente ao valor da produção, é a própria renda de Hotelling. De acordo com Hartwick (1977), a condição para a manutenção das possibilidades de consumo de uma sociedade é o investimento da renda de Hotelling em ativos físicos, com o objetivo de manter o estoque de capital constante diante do decréscimo do recurso. Ou seja, a Regra de Hartwick prescreve que uma sociedade deve usar a renda de seus recursos para financiar a diversificação da economia com objetivo de compensar a depreciação de seu capital natural, que não poderá mais sustentar o seu consumo. Caso a renda de Hotelling seja consumida, haverá uma inevitável queda no bem-estar da sociedade decorrente da sua incapacidade de manter o consumo per capita ao longo do tempo. Sollow (1974) e Dasgupta e Heal (1974) chegam a conclusões similares a respeito da dependência de recursos exauríveis e a sustentabilidade do consumo ao longo do tempo.

A Figura 1 ilustra os componentes da renda mineral. Mesmo no equilíbrio competitivo, e desde que os direitos de propriedade sejam claramente estabelecidos, haverá uma renda decorrente da necessidade de compensar o proprietário pelo decréscimo de seu estoque de capital. Nesse sentido, a produção ocorre no ponto em que o preço é maior que o custo marginal de extração e a diferença entre ambos é a própria renda de Hotelling. Pela regra de Hartwick, esta renda deve ser investida com vistas a evitar uma queda do bem-estar da sociedade. Caso esta renda seja consumida, o estoque de capital da sociedade diminuirá e, consequentemente, suas 
possibilidades de consumo futuro. Apenas o excedente do produtor, que também é um dos componentes da renda total, pode ser consumido.

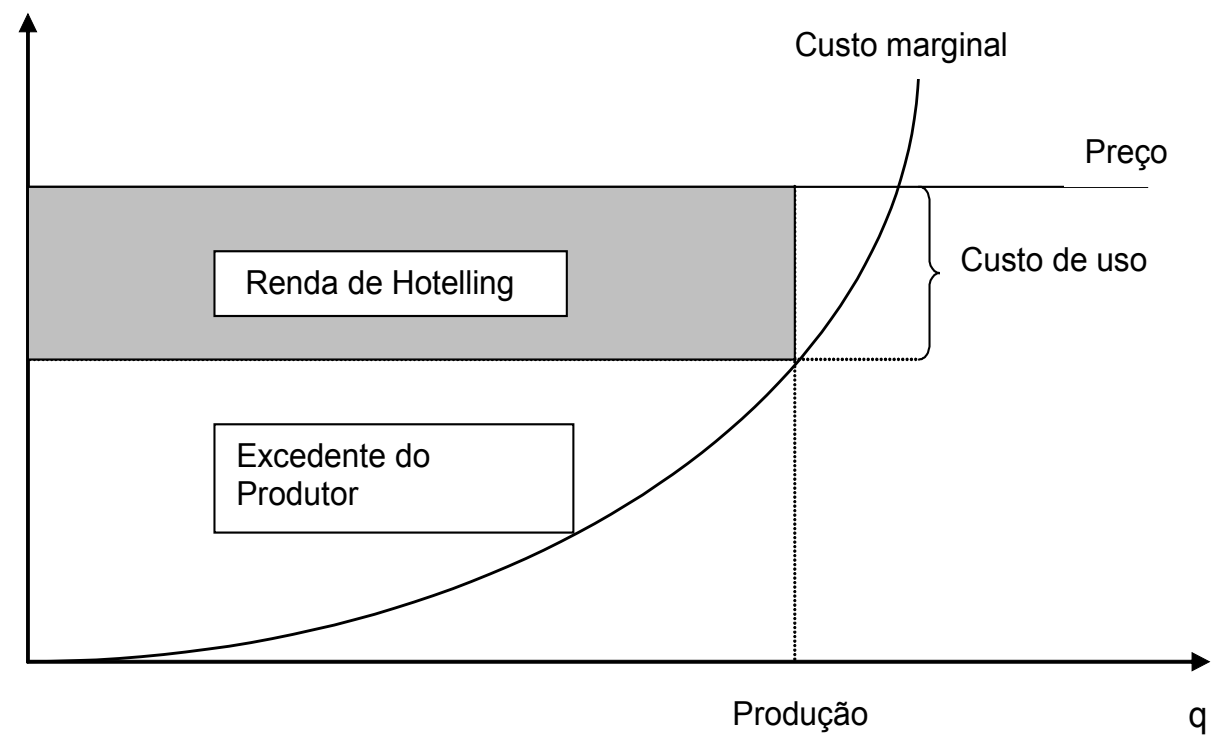

Figura 1- Renda de Hotelling e Produção de Recurso

Fonte: Postali (2002), p.20.

Se não houvesse direitos de propriedade definidos (common pool), o produtor não perceberia o custo de uso, resultando em uma extração predatória e em uma consequente dissipação de rendas. Como se nota na Figura 1, se o custo de uso desaparecer, a produção ocorrerá no ponto em que o preço é igual ao custo marginal, resultando em uma quantidade extraída acima daquela que seria socialmente ótima. Desta forma, a trajetória de extração torna-se diferente daquela que maximiza o bem-estar social.

A compensação pela perda de seu estoque de capital está na raiz da necessidade de indenização dos municípios pelas atividades de produção de petróleo. ${ }^{3,4}$ À medida

4 Deve-se ressaltar, entretanto, que no Brasil, no caso do petróleo, boa parte da produção se dá na plataforma continental (offshore), de modo que, de fato, as atividades de produção não se dão no território do município para caracterizar um direito de indenização em si. A fim de se superar esta controvérsia legal, a legislação criou o conceito de "confrontação" para tentar compensar essa indenização. Assim, quando a lavra ocorre na plataforma continental, um município é considerado confrontante, de acordo com a projeção de sua circunscrição geográfica em direção ao mar, e as receitas de royalties a que tem direito de receber são proporcionais à produção dos poços dentro 
que o processo produtivo se desenrola, o estoque de ativos diminui por conta da exaustão do recurso. A União, como proprietária constitucional dos recursos tem o direito de auferir as suas rendas e de investi-las na preservação do bem-estar da sociedade. Neste contexto, os municípios produtores e confrontantes, além dos afetados pela produção de petróleo, são ressarcidos não apenas para compensar eventuais impactos deletérios da indústria extrativa sobre as localidades, mas também para alocar ao público, como legítimo proprietário dos recursos, as rendas que lhe são de direito. Além disso, a determinação da Lei do Petróleo de que as prefeituras devem investir (e não consumir) as rendas auferidas, na forma de royalties, também é consistente com a regra de Hartwick, pois procura preservar a capacidade de consumo ao longo do tempo através da manutenção do estoque de capital do município.

Em resumo, as transferências de renda dos recursos não renováveis para os governos locais afetados, conjugadas com a obrigatoriedade de investimentos produtivos (em estoque de capital físico ou humano) ou na área social, obedecem a uma lógica intertemporal de maximização de consumo "intergeracional". Esta é a rationale para a distribuição de rendas do petróleo da União para as localidades.

Todavia, os critérios atuais que orientam a partilha de rendas do petróleo - royalties e participações especiais - foram definidos pelo marco regulatório inaugurado em 1997 pela Lei do Petróleo e contêm severas distorções (SERRA, 2003). Duas categorias de localidades estão aptas a receber essas receitas: os municípios produtores e os municípios afetados por atividades petroleiras. Os maiores montantes financeiros são dirigidos aos municípios produtores. Quando a lavra ocorre na plataforma continental, o município é caracterizado como um produtor de acordo com a projeção de sua circunscrição geográfica em direção ao mar e as receitas de royalties a que tem direito de receber é proporcional à produção dos poços dentro desta projeção. Assim, dependendo do formato de sua costa, o município inclui mais ou menos poços produtivos à sombra de sua projeção oceânica, recebendo transferências de royalties de acordo com esta produção.

Em relação à segunda regra, que define se um município sofre impactos da indústria do petróleo de modo a ser compensado por receitas de royalties, todas as atividades de embarque e desembarque de petróleo e gás (incluindo o transporte por meio de gasodutos e oleodutos) estão incluídas nos critérios de elegibilidade.

Como a maior parte da produção nacional de petróleo se realiza na Bacia de Campos, no litoral do Rio de Janeiro, os maiores beneficiários de receitas de royal-

desta projeção. Além disso, a fração das receitas destinadas aos confrontantes é superior à alocada aos produtores no sentido estrito. Por exemplo, as participações especiais são distribuídas apenas aos municípios confrontantes. Agradecemos a um parecerista anônimo estas observações. 
ties estão neste Estado. As Tabelas 1 e 2 relatam os maiores beneficiários em 2009 em montante bruto e em valores per capita, respectivamente. Os municípios fluminenses destacam-se sob os dois critérios, mas também se observam grandes beneficiários em outros estados produtores, como Rio Grande do Norte, Espírito Santo, Sergipe e Bahia. Além disso, devido à crescente produção na Bacia de Santos, alguns municípios do litoral de São Paulo têm se beneficiado da distribuição dos royalties.

Tabela 1 - Maiores Beneficiários de Royalties e Participações Especiais em 2009, em R\$

\begin{tabular}{llc}
\hline UF & Beneficiário & Valores Brutos (R\$) \\
\hline RJ & Campos dos Goytacazes & $775.875 .811,33$ \\
RJ & Macaé & $339.486 .873,04$ \\
RJ & Rio das Ostras & $204.061 .901,28$ \\
RJ & São João da Barra & $142.314 .419,81$ \\
RJ & Cabo Frio & $119.806 .771,97$ \\
RJ & Quissamã & $84.983 .388,49$ \\
ES & Presidente Kennedy & $66.193 .393,48$ \\
RJ & Angra dos Reis & $66.102 .890,96$ \\
RJ & Parati & $62.914 .490,61$ \\
RJ & Casimiro de Abreu & $50.854 .999,35$ \\
\hline
\end{tabular}

Fonte: Info Royalties/UCAM.

Tabela 2 - Maiores Beneficiários de Royalties e Participações Especiais em 2009, em Valores Per Capita Nominais, em R\$

\begin{tabular}{llc}
\hline UF & Município & Valores Per Capita R\$ \\
\hline ES & Presidente Kennedy & $6.196,72$ \\
RJ & São João da Barra & $4.843,92$ \\
RJ & Quissamã & $4.449,16$ \\
RJ & Rio das Ostras & $2.053,35$ \\
RJ & Carapebus & $1.940,16$ \\
RJ & Parati & $1.837,56$ \\
RJ & Macaé & $1.821,04$ \\
RJ & Campos dos Goytacazes & $1.787,85$ \\
RJ & Casimiro de Abreu & $1.734,13$ \\
RJ & Armação dos Búzios & $1.440,24$ \\
\hline
\end{tabular}

Fonte: Info Royalties/UCAM. 
A expressividade dos recursos advindos da atividade petrolífera e o forte impacto nas finanças de algumas prefeituras despertam preocupações quanto ao uso eficiente destas rendas. Como a legislação procura nortear e restringir a aplicação destes recursos, evitando que se destinem ao pagamento de dívidas e da folha salarial, espera-se que eles recursos sejam aplicados na melhoria das condições sociais e da infraestrutura dos municípios beneficiados. Uma das grandes preocupações, provenientes da literatura sobre a maldição dos recursos naturais, é o uso ineficiente de tais rendas, comprometendo o bem-estar futuro destas populações. No limite, tais recursos podem dar margem ao desperdício e até mesmo à corrupção (MEHLUM et al., 2006).

\section{Estratégia Empírica}

A fim de se investigar se as rendas do petróleo impactaram positivamente nos indicadores sociais ao longo da última década, utilizamos o Índice FIRJAN de Desenvolvimento Municipal, elaborado pela Federação das Indústrias do Estado do Rio de Janeiro. Trata-se de uma medida que agrega diversos indicadores sociais, com o objetivo de definir uma medida de grau de desenvolvimento municipal. Tal como o IDH, ${ }^{5}$ o IFDM varia entre 0 e 1 : quanto mais próximo da unidade, maior o grau de desenvolvimento social do Município. O IFDM/FIRJAN está calculado para os anos de 2000, 2005, 2006 e 2007.

O motivo da escolha deste indicador foi sua disponibilidade de informação para todos os municípios brasileiros e informações referentes a períodos de tempo razoavelmente posteriores à entrada em vigor da Lei do Petróleo, que ocorreu em 1997. Considerando que investimentos produtivos e políticas de melhora social levam tempo para gerar resultados, a utilização de tais dados é importante para captar efeitos de prazo mais longo.

O IFDM é calculado a partir da média aritmética simples de três componentes relativos a indicadores de Educação, Saúde e Emprego \& Renda. A Tabela 3 resume a composição de cada um deles. ${ }^{6}$

5 O Índice de Desenvolvimento Humano (IDH) só está disponível até o ano 2000, quando se realizou o Censo Demográfico.

6 Ver detalhes metodológicos em FIRJAN (2010). 


\section{Tabela 3 - Composição do Índice FIRJAN de Desenvolvimento Municipal IFDM.}

\begin{tabular}{lll}
\hline \multicolumn{1}{c}{ Índice } & \multicolumn{1}{c}{ Composição } & \multicolumn{1}{c}{ Fonte } \\
\hline IFDM - Educação & Taxa de Matrícula na Educação Infantil; & Ministério da Educação \\
& Taxa de Abandono; & \\
& Taxa de Distorção Idade-Série; & \\
& Percentual de Docentes com Ensino Superior; & \\
& Média de Horas-Aula Diárias; & \\
& Resultados do IDEB. & \\
\hline IFDM - Saúde & Número de Consultas Pré-Natal; & Ministério da Saúde \\
& Taxa de Óbitos Infantis por Causas Evitáveis; & \\
& Taxa de Óbitos Infantis por Causas Maldefinidas. & \\
\hline IFDM - Emprego \& Renda & Geração de Emprego Formal; & Ministério do Trabalho e Emprego \\
& Estoque de Emprego Formal; & \\
& Salários Médios no Emprego Formal. & \\
\hline IFDM & Média Aritmética dos Três Indicadores Acima & \\
\hline
\end{tabular}

Fonte: FIRJAN (2010).

De acordo com a FIRJAN (2010), o IFDM - Emprego \& Renda busca acompanhar a evolução do mercado formal de trabalho com base em dois bancos de dados do Ministério do Trabalho e do Emprego - RAIS e CAGED. O IFDM - Educação, por sua vez, destina-se a captar a oferta e a qualidade da educação básica - fundamental e pré-escola - tanto do sistema público quanto do privado; seus indicadores são extraídos do Índice de Desenvolvimento da Educação Básica (IDEB) e do Censo Escolar. Já o IFDM - Saúde resulta da média ponderada de três indicadores provenientes do Sistema de Informações sobre Mortalidade (SIM) e o Sistema de Informações sobre Nascidos Vivos (SINASC), ambos do Ministério da Saúde.

A Tabela 4 apresenta as médias dos IFDM por componente e por grupo de municípios - beneficiários e não beneficiários de royalties e participações especiais - para os anos que compõem a base de dados. A última coluna apresenta a estatística tStudent do teste de igualdade de médias de ambos os grupos $\left(\mathrm{H}_{0}\right.$ : Média dos não beneficiários - média dos beneficiários $=0$ ), para cada um dos anos. Verifica-se que apenas para os anos de 2005 e 2006 o IFDM - Emprego\&Renda foi estatisticamente superior para os municípios beneficiários em relação aos não beneficiários. Quanto aos demais indicadores, as médias dos municípios beneficiários mostraram-se estatisticamente inferiores às médias dos não beneficiários, o que não deixa de ser um resultado curioso. 
Tabela 4 - Índice FIRJAN de Desenvolvimento Municipal

Média por Grupo de Municípios - H0: Médias Iguais

\begin{tabular}{|c|c|c|c|}
\hline & $\begin{array}{l}\text { Beneficiários } \\
\text { (a) }\end{array}$ & $\begin{array}{l}\text { Não Beneficiários } \\
\text { (b) }\end{array}$ & $\begin{array}{c}\text { Estatística t } \\
\mathrm{H}_{0}: \text { Média }(\mathrm{b})-\text { Média }(\mathrm{a})=0\end{array}$ \\
\hline \multicolumn{4}{|l|}{ Geral } \\
\hline 2000 & 0.4932 & 0.5304 & $8.09^{\star * \star}$ \\
\hline 2005 & 0.5735 & 0.5969 & $5.01^{* \star \star}$ \\
\hline 2006 & 0.5876 & 0.6018 & $2.71^{\star * *}$ \\
\hline 2007 & 0.5907 & 0.6191 & $5.83^{\star * \star}$ \\
\hline \multicolumn{4}{|c|}{ Educação } \\
\hline 2000 & 0.5123 & 0.5697 & $9.98^{\star * *}$ \\
\hline 2005 & 0.6151 & 0.6542 & $7.70^{\star \star \star}$ \\
\hline 2006 & 0.6150 & 0.6526 & $6.72^{\star * \star}$ \\
\hline 2007 & 0.6380 & 0.6931 & $10.34^{\star \star \star}$ \\
\hline \multicolumn{4}{|c|}{ Saúde } \\
\hline 2000 & 0.6110 & 0.6596 & $10.04^{\star \star \star}$ \\
\hline 2005 & 0.6829 & 0.7313 & $10.41^{\star \star *}$ \\
\hline 2006 & 0.7150 & 0.7457 & $6.18^{\star \star \star}$ \\
\hline 2007 & 0.7270 & 0.7667 & $8.30^{\star * *}$ \\
\hline \multicolumn{4}{|c|}{ Emprego/Renda } \\
\hline 2000 & 0.3563 & 0.3620 & 0.873 \\
\hline 2005 & 0.4225 & 0.4051 & $-2.48^{\star *}$ \\
\hline 2006 & 0.4328 & 0.4070 & $-3.14^{* \star *}$ \\
\hline 2007 & 0.4073 & 0.3975 & -1.25 \\
\hline
\end{tabular}

Fonte: Elaboração própria, com base nos dados da FIRJAN. ${ }^{* *}$ Significativo a $1 \%$; ${ }^{* *}$ significativo a $5 \%$.

Conforme já descrito anteriormente, o IFDM é um indicador construído de forma a variar entre 0 e 1 , nos mesmos moldes do Índice de Desenvolvimento Humano (IDH). O nosso interesse não é verificar se as receitas do petróleo causaram impacto no valor absoluto do índice em si, mas sim na posição do município em relação aos demais, no que se refere ao indicador. Portanto, ao invés de se trabalhar com o IFDM propriamente dito, a variável dependente utilizada foi um índice normalizado, calculado como:

$$
I F D M_{-} r e l_{i t}=\ln \left(\frac{I F D M_{i t}}{I F D M_{t}}\right)
$$


Assim, o IFDM_rel de um determinado município é positivo ou negativo conforme seu IFDM é maior ou menor do que a média nacional naquele ano. Deste modo, busca-se determinar se as receitas petrolíferas afetaram a distância do indicador municipal em relação à média nacional.

Com o objetivo de investigar esta questão, a estratégia empírica consistiu em estimar o seguinte modelo de efeitos fixos:

$I F D M_{-} r e l_{i t}=\alpha+f_{i}+\beta_{1} R O Y_{i t}+\beta_{2} P I B P C_{i t}+\beta_{3} P O P_{i t}+\beta_{4} D_{-}$GRANDES $_{i t}+\varepsilon_{i t}$

Onde:

- IFDM_rel ${ }_{i t}$ é o Índice FIRJAN de Desenvolvimento Municipal relativo para o município $i$ no ano $t$. Cada componente do indicador foi testado separadamente;

- $R O Y_{i t}$ é o total de royalties e participações especiais recebidos pelo município $i$ no ano $t$;

- $\quad$ PIBPC $_{i t}$ é o logaritmo do PIB per capita do município $i$ no ano $t$;

- $\quad P O P_{i t}$ é o logaritmo da população municipal;

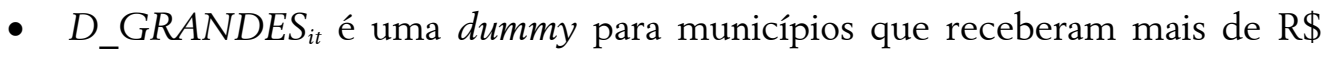
1000,00 per capita em royalties e participações especiais, com o objetivo de investigar se os grandes beneficiários apresentam um perfil diferenciado em relação aos demais.

Na Equação (2), $f_{i}$ é o efeito fixo do município $i, \alpha$ é a constante de estimação e $\varepsilon_{\text {it }}$ um ruído branco. O modelo de efeitos fixos permite controlar pelas características não observáveis das localidades, mas que permanecem constantes ao longo do tempo. ${ }^{7}$ Dummies de ano foram inseridas na estimação, visando controlar para choques macroeconômicos globais. A hipótese de identificação é de que $E\left[\varepsilon_{i t} \mid R O Y_{i t}\right]=0$, ou seja, não deve existir correlação entre os royalties recebidos pelos municípios e as demais variáveis não controladas no modelo, a fim de que o coeficiente estima-

7 Conforme observação de um parecerista anônimo, economias fortemente dependentes de petróleo podem ter seu PIB artificialmente inflado, com possível distorção na sua renda real. Desta forma, o mais apropriado seria utilizar o "PNB" municipal, cujo cálculo inexiste. Como o modelo de efeitos fixos controla por características não observáveis que permanecem constantes ao longo do tempo, se esse viés for invariante no tempo (como é de se supor que seja, já que os municípios dependentes da indústria do petróleo não mudam ao longo do tempo), ele estará controlado. 
do seja apropriadamente identificado (WOOLDRIDGE, 2002). Trata-se de uma hipótese relativamente aceitável, tendo em vista que as distorções na distribuição dos royalties acima apontadas são controladas por efeitos fixos.

Com relação à variável de interesse - rendas do petróleo - foram testadas separadamente duas medidas alternativas da influência dos royalties no município: a razão royalties+participações especiais em relação à população e a razão royalties+participações especiais em relação à receita corrente do município. A primeira tem como propósito investigar a relação entre abundância destes recursos e os indicadores sociais em tela, ao passo que a segunda visa construir uma medida de grau de dependência do orçamento municipal em relação às receitas do petróleo. Esta última permite avaliar se as prefeituras altamente dependentes de royalties revertem estes recursos em benefícios sociais, conforme se espera.

A Tabela 5 resume as estatísticas descritivas das variáveis independentes utilizadas no estudo. Como se pode observar, há uma grande heterogeneidade no volume de receitas de royalties e participações especiais auferidas pelos municípios brasileiros, fruto das distorções na distribuição destas rendas, conforme mencionado anteriormente.

Tabela 5 - Estatísticas Descritivas das Variáveis Independentes

\begin{tabular}{lcrrrr}
\hline Variável & Obs. & Média & D. P. & Mín. & Máx. \\
\hline 2000 & & & & & \\
Royalty per capita & 4615 & 3.665 & 43.903 & 0.000 & 1776.249 \\
Royalty/Receita Corrente & 4615 & 0.004 & 0.034 & 0.000 & 0.957 \\
PIB per capita & 4615 & 5.040 & 6.258 & 0.561 & 171.805 \\
População & 4615 & 32199 & 193948 & 789 & 10009231 \\
\hline 2005 & & & & & \\
Royalty per capita & 4117 & 7.636 & 86.844 & 0.000 & 3386.098 \\
Royalty/Receita Corrente & 4117 & 0.004 & 0.029 & 0.000 & 0.624 \\
PIB per capita & 4117 & 4.863 & 5.552 & 0.760 & 132.530 \\
População & 4117 & 35929 & 223808 & 823 & 10927985 \\
\hline 2006 & & & & & \\
Royalty per capita & 5409 & 9.162 & 124.963 & 0.000 & 6239.154 \\
Royalty/ Receita Corrente & 5409 & 0.004 & 0.033 & 0.000 & 0.703 \\
PIB per capita & 5409 & 4.898 & 5.700 & 0.720 & 128.732 \\
População & 5409 & 33587 & 199284 & 828 & 11016703 \\
\hline
\end{tabular}


(Continuação)

\begin{tabular}{lrrrrr}
\hline 2007 & & & & & \\
Royalty per capita & 5283 & 7.382 & 86.243 & 0.000 & 3222.101 \\
Royalty / Receita Corrente & 5283 & 0.004 & 0.028 & 0.000 & 0.672 \\
PIB per capita & 5283 & 5.366 & 6.121 & 0.967 & 137.067 \\
População & 5283 & 33343 & 200013 & 804 & 10886518 \\
\hline
\end{tabular}

Fonte: Elaboração própria, com base nos dados do IBGE e Info Royalties/UCAM.

\section{Resultados}

As Tabelas 6 a 9 apresentam os resultados das estimações para o índice como um todo e para cada um dos seus componentes - Educação, Saúde e Emprego\&Renda. As Especificações 1 e 2 utilizam como variável independente o valor dos royalties per capita auferidos pelo município, ao passo que as especificações 3 e 4 utilizam a relação entre royalties e receita corrente Municipal.

No que se refere ao IFDM como um todo (Tabela 6), observa-se que a abundância de recursos (medida pelos royalties per capita) não afeta significativamente o indicador social em estudo. No entanto, quando se utiliza a medida de dependência de recursos (royalties sobre receita corrente), verifica-se que quanto mais dependente de rendas do petróleo, menor o IFDM do Município em relação à média nacional. Apesar de ser pequeno, o efeito é estatisticamente significativo a $1 \%$.

Como se pode observar, as demais variáveis de controle obtiveram os sinais esperados. Além disso, os grandes beneficiários não apresentam evolução diferenciada no seu indicador de desenvolvimento municipal, tendo em vista que a dummy que controla este efeito se mostrou não significativa. 
Tabela 6 - Resultados do Modelo de Efeitos Fixos Variável Dependente: IFDM/FIRJAN Relativo

\begin{tabular}{|c|c|c|c|c|}
\hline & \multicolumn{4}{|c|}{ Especificação } \\
\hline & 1 & 2 & 3 & 4 \\
\hline \multirow[t]{2}{*}{ Royalties per capita } & $4.71 \mathrm{e}-06$ & $1.53 e-06$ & - & - \\
\hline & $(7.09 \mathrm{e}-06)$ & $(8.94 \mathrm{e}-06)$ & & \\
\hline \multirow[t]{2}{*}{ Royalties/Receita Corrente } & - & - & $-0.000412^{\star \star \star}$ & $-0.000412^{* * *}$ \\
\hline & & & $(9.80 e-05)$ & $(9.80 e-05)$ \\
\hline \multirow[t]{2}{*}{ Dummy >=1000 per capita } & - & 0.0113 & - & -0.00249 \\
\hline & & $(0.0181)$ & & $(0.0125)$ \\
\hline \multirow[t]{2}{*}{ PIB per capita } & $0.0523^{\star \star *}$ & $0.0523^{\star \star \star}$ & $0.0523^{\star \star \star}$ & $0.0523^{\star \star \star}$ \\
\hline & $(0.00324)$ & $(0.00324)$ & $(0.00363)$ & $(0.00363)$ \\
\hline \multirow[t]{2}{*}{ População } & $0.0544^{* * *}$ & $0.0544^{* * *}$ & $0.0536^{\star * *}$ & $0.0536^{* \star *}$ \\
\hline & $(0.00608)$ & $(0.00608)$ & $(0.00679)$ & $(0.00679)$ \\
\hline \multirow[t]{2}{*}{ Dummy 2005} & $-0.0560^{\star \star \star}$ & $-0.0560^{\star \star *}$ & $-0.0617^{\star \star \star}$ & $-0.0617^{\star \star \star}$ \\
\hline & $(0.00136)$ & $(0.00136)$ & $(0.00151)$ & $(0.00151)$ \\
\hline \multirow[t]{2}{*}{ Dummy 2006} & $-0.0772^{* * *}$ & $-0.0772^{\star \star \star}$ & $-0.0836^{\star \star *}$ & $-0.0836^{\star * \star}$ \\
\hline & $(0.00139)$ & $(0.00139)$ & $(0.00147)$ & $(0.00147)$ \\
\hline \multirow[t]{2}{*}{ Dummy 2007} & $-0.0712^{\star \star \star}$ & $-0.0712^{\star \star *}$ & $-0.0779^{\star \star \star}$ & $-0.0779^{\star \star \star}$ \\
\hline & $(0.00155)$ & $(0.00155)$ & $(0.00165)$ & $(0.00165)$ \\
\hline \multirow[t]{2}{*}{ Constante } & $0.313^{\star * *}$ & $0.313^{\star \star *}$ & $0.336^{\star \star *}$ & $0.336^{\star * *}$ \\
\hline & $(0.0582)$ & $(0.0582)$ & $(0.0652)$ & $(0.0652)$ \\
\hline \# Observações & 22176 & 22176 & 19424 & 19424 \\
\hline R-quadrado & 0.231 & 0.231 & 0.281 & 0.281 \\
\hline \# de Municípios & 5563 & 5563 & 5534 & 5534 \\
\hline
\end{tabular}

Significativo a $1 \%,{ }^{* *}$ Significativo a $5 \%,{ }^{*}$ Significativo a $10 \%$.

Desvio-Padrão entre Parênteses.

No que se refere ao IFDM-Educação (Tabela 7), observa-se que apenas na Especificação 1 a abundância de recursos se revelou significativa a $10 \%$, o que não se permite concluir pela existência de algum efeito positivo. A dependência de recursos não acarreta nenhum impacto na evolução dos indicadores de educação, conforme se observa pelas Especificações 3 e 4. Os resultados para os indicadores de saúde reunidos no IFDM (Tabela 8) são análogos. Deste modo, conclui-se que não existem evidências de impactos significativos das rendas do petróleo sobre indicadores de saúde e educação dos municípios contemplados, para o período investigado. 
Tabela 7 - Resultados do Modelo de Efeitos Fixos Variável Dependente: IFDM EDUCAÇÃO/FIRJAN Relativo

\begin{tabular}{|c|c|c|c|c|}
\hline & \multicolumn{4}{|c|}{ Especificação } \\
\hline & 1 & 2 & 3 & 4 \\
\hline Royalties per capita & $\begin{array}{c}1.47 \mathrm{e}-05^{\star} \\
(7.88 \mathrm{e}-06)\end{array}$ & $\begin{array}{r}1.33 e-05 \\
(9.09 e-06)\end{array}$ & & \\
\hline Royalties/Receita Corrente & & & $\begin{array}{r}1.96 \mathrm{e}-05 \\
(0.000219)\end{array}$ & $\begin{array}{l}0.0000186 \\
(0.000219)\end{array}$ \\
\hline Dummy >=1000 per capita & & $\begin{array}{l}0.00512 \\
(0.0259)\end{array}$ & & $\begin{array}{r}0.0182773 \\
(0.0259)\end{array}$ \\
\hline PIB per capita & $\begin{array}{c}0.0682^{* * *} \\
(0.00383)\end{array}$ & $\begin{array}{c}0.0682^{* * *} \\
(0.00383)\end{array}$ & $\begin{array}{c}0.0600^{* * *} \\
(0.00443)\end{array}$ & $\begin{array}{c}0.0599^{\star * *} \\
(0.00443)\end{array}$ \\
\hline População & $\begin{array}{c}0.0913^{\star * *} \\
(0.00758)\end{array}$ & $\begin{array}{c}0.0913^{\star * *} \\
(0.00758)\end{array}$ & $\begin{array}{c}0.0764^{\star * *} \\
(0.00871)\end{array}$ & $\begin{array}{c}0.0763^{* * *} \\
(0.00871)\end{array}$ \\
\hline Dummy 2005 & $\begin{array}{c}-0.0215^{\star \star *} \\
(0.00168)\end{array}$ & $\begin{array}{c}-0.0215^{\star * \star} \\
(0.00168)\end{array}$ & $\begin{array}{c}-0.0350^{\star * \star} \\
(0.00188)\end{array}$ & $\begin{array}{c}-0.0350^{\star * \star} \\
(0.00188)\end{array}$ \\
\hline Dummy 2006 & $\begin{array}{l}-0.0158^{* * *} \\
(0.00172)\end{array}$ & $\begin{array}{c}-0.0158^{* * *} \\
(0.00172)\end{array}$ & $\begin{array}{l}-0.0285^{\star \star *} \\
(0.00186)\end{array}$ & $\begin{array}{c}-0.0285^{\star * \star} \\
(0.00186)\end{array}$ \\
\hline Dummy 2007 & $\begin{array}{l}-0.00633^{\star \star \star} \\
(0.00199)\end{array}$ & $\begin{array}{l}-0.00633^{\star \star \star} \\
(0.00199)\end{array}$ & $\begin{array}{c}-0.0192^{* * *} \\
(0.00214)\end{array}$ & $\begin{array}{c}-0.0192^{* * *} \\
(0.00214)\end{array}$ \\
\hline Constante & $\begin{array}{r}0.0263 \\
(0.0723)\end{array}$ & $\begin{array}{r}0.0263 \\
(0.0723)\end{array}$ & $\begin{array}{c}0.200^{\star *} \\
(0.0832)\end{array}$ & $\begin{array}{c}0.200^{* *} \\
-0.0832144\end{array}$ \\
\hline \# Observações & 22176 & 22176 & 19424 & 19424 \\
\hline R-quadrado & 0.050 & 0.050 & 0.052 & 0.052 \\
\hline \# de Municípios & 5563 & 5563 & 5534 & 5534 \\
\hline
\end{tabular}

*** Significativo a $1 \%, * *$ Significativo a $5 \%, *$ Significativo a $10 \%$.

Desvio-Padrão entre Parênteses. 
Tabela 8 - Resultados do Modelo de Efeitos Fixos Variável Dependente: IFDM SAÚDE/FIRJAN Relativo

\begin{tabular}{|c|c|c|c|c|}
\hline & \multicolumn{4}{|c|}{ Especificação } \\
\hline & 1 & 2 & 3 & 4 \\
\hline \multirow[t]{2}{*}{ Royalties per capita } & $-3.04 \mathrm{e}-06$ & $-7.15 e-06$ & & \\
\hline & $(5.81 e-06)$ & $(7.85 e-06)$ & & \\
\hline \multirow[t]{2}{*}{ Royalties/Receita Corrente } & & & $-1.79 e-05$ & $-1.75 e-05$ \\
\hline & & & $(9.53 e-05)$ & $(9.52 \mathrm{e}-05)$ \\
\hline \multirow[t]{2}{*}{ Dummy >=1000 per capita } & & 0.0146 & & -0.00746 \\
\hline & & $(0.0172)$ & & $(0.0139)$ \\
\hline \multirow[t]{2}{*}{ PIB per capita } & $0.0192^{\star \star *}$ & $0.0192^{\star * \star}$ & $0.0180^{\star * \star}$ & $0.0180^{\star \star *}$ \\
\hline & $(0.00385)$ & $(0.00385)$ & $(0.00434)$ & $(0.00434)$ \\
\hline \multirow[t]{2}{*}{ População } & $0.0140^{*}$ & $0.0140^{*}$ & 0.0105 & 0.0105 \\
\hline & $(0.00746)$ & $(0.00746)$ & $(0.00826)$ & $(0.00826)$ \\
\hline \multirow[t]{2}{*}{ Dummy 2005} & $0.0365^{\star \star \star}$ & $0.0365^{\star \star \star}$ & $0.0357^{\star \star \star}$ & $0.0357^{\star \star \star}$ \\
\hline & $(0.00175)$ & $(0.00175)$ & $(0.00194)$ & $(0.00194)$ \\
\hline \multirow[t]{2}{*}{ Dummy 2006} & $0.0441^{* * *}$ & $0.0441^{\star \star *}$ & $0.0429^{\star \star \star}$ & $0.0429^{\star \star \star}$ \\
\hline & $(0.00176)$ & $(0.00176)$ & $(0.00189)$ & $(0.00189)$ \\
\hline \multirow[t]{2}{*}{ Dummy 2007} & $0.0520^{\star * \star}$ & $0.0520^{* * *}$ & $0.0506^{* * *}$ & $0.0506^{* \star \star}$ \\
\hline & $(0.00195)$ & $(0.00195)$ & $(0.00210)$ & $(0.00210)$ \\
\hline \multirow[t]{2}{*}{ Constante } & $0.765^{\star \star \star}$ & $0.765^{\star \star \star}$ & $0.810^{\star \star \star}$ & $0.810^{\star \star \star}$ \\
\hline & $(0.0713)$ & $(0.0713)$ & $(0.0792)$ & $(0.0792)$ \\
\hline \# Observações & 22176 & 22176 & 19424 & 19424 \\
\hline R-quadrado & 0.105 & 0.105 & 0.102 & 0.102 \\
\hline \# de Municípios & 5563 & 5563 & 5534 & 5534 \\
\hline
\end{tabular}

*** Significativo a 1\%, ** Significativo a 5\%, * Significativo a $10 \%$.

A Tabela 9 traz os resultados para o IFDM - Emprego\&Renda. Como se pode observar, a abundância de recursos do petróleo não acarreta impactos significativos nos indicadores relativos ao mercado de trabalho formal, mas a dependência de royalties (rendas/receita corrente) tem um impacto negativo sobre este indicador. Trata-se de um resultado instigante, que merece investigações mais profundas. Ele pode estar indicando que a dependência de transferências de royalties gera uma informalização maior das relações de trabalho. Quando se leva em conta que a legislação pró́be a alocação dos royalties na contratação de pessoal pelas prefeituras, o resultado pode indicar a proliferação de mecanismos de terceirização e contratação de ONGs, por 
exemplo, visando burlar as restrições legais. Essa é uma preocupação relevante, que já foi objeto de notícias na imprensa. ${ }^{8} \mathrm{O}$ efeito dos royalties sobre as relações de trabalho em geral (e não apenas sobre o setor formal) requereria o uso de indicadores só disponíveis pela pesquisa censitária, a qual se encontra em andamento (2010) e que constitui uma extensão natural deste trabalho. Assim, este resultado abre a possibilidade de se investigar se houve, por força da lei, um deslocamento do trabalho formal para o informal.

\section{Tabela 9 - Resultados do Modelo de Efeitos Fixos Variável Dependente: IFDM EMPREGO \& RENDA/FIRJAN Relativo}

\begin{tabular}{|c|c|c|c|c|}
\hline & \multicolumn{4}{|c|}{ Especificação } \\
\hline & 1 & 2 & 3 & 4 \\
\hline \multirow[t]{2}{*}{ Royalties per capita } & $-1.60 e-06$ & $-5.44 e-06$ & & \\
\hline & $(1.79 \mathrm{e}-05)$ & $(2.18 \mathrm{e}-05)$ & & \\
\hline \multirow[t]{2}{*}{ Royalties/Receita Corrente } & & & $-0.00150^{\star * *}$ & $-0.00150^{\star * *}$ \\
\hline & & & $(0.000290)$ & $(0.000290)$ \\
\hline \multirow[t]{2}{*}{ Dummy >=1000 per capita } & & 0.0137 & & -0.0293 \\
\hline & & $(0.0438)$ & & $(0.0372)$ \\
\hline \multirow[t]{2}{*}{ PIB per capita } & $0.0625^{\star \star \star}$ & $0.0625^{\star \star \star}$ & $0.0691^{\star * \star}$ & $0.0692^{* * *}$ \\
\hline & $(0.00835)$ & $(0.00835)$ & $(0.00920)$ & $(0.00920)$ \\
\hline \multirow[t]{2}{*}{ População } & $0.0265^{*}$ & $0.0265^{*}$ & $0.0399^{* \star}$ & $0.0400^{* *}$ \\
\hline & $(0.0153)$ & $(0.0153)$ & $(0.0166)$ & $(0.0166)$ \\
\hline \multirow[t]{2}{*}{ Dummy 2005} & $-0.158^{\star \star \star}$ & $-0.158^{\star \star \star}$ & $-0.161^{\star \star *}$ & $-0.161^{\star \star \star}$ \\
\hline & $(0.00332)$ & $(0.00332)$ & $(0.00359)$ & $(0.00360)$ \\
\hline \multirow[t]{2}{*}{ Dummy 2006} & $-0.211^{* * *}$ & $-0.211^{\star \star \star}$ & $-0.216^{\star \star \star}$ & $-0.216^{\star \star *}$ \\
\hline & $(0.00332)$ & $(0.00332)$ & $(0.00345)$ & $(0.00345)$ \\
\hline \multirow[t]{2}{*}{ Dummy 2007} & $-0.222^{\star \star *}$ & $-0.222^{\star \star *}$ & $-0.227^{\star * *}$ & $-0.227^{\star \star *}$ \\
\hline & $(0.00360)$ & $(0.00360)$ & $(0.00376)$ & $(0.00376)$ \\
\hline \multirow[t]{2}{*}{ Constante } & $0.417^{\star \star \star}$ & $0.417^{\star \star \star}$ & $0.293^{*}$ & $0.293^{*}$ \\
\hline & $(0.147)$ & $(0.147)$ & $(0.159)$ & $(0.159)$ \\
\hline \# Observações & 22176 & 22176 & 19424 & 19424 \\
\hline R-quadrado & 0.325 & 0.325 & 0.357 & 0.357 \\
\hline \# de Municípios & 5563 & 5563 & 5534 & 5534 \\
\hline
\end{tabular}

*** Significativo a $1 \%, * *$ Significativo a $5 \%, *$ Significativo a $10 \%$.

Desvio-Padrão entre Parênteses.

8 Ver, por exemplo: http://www.ecodebate.com.br/2008/04/15/royalties-lucro-com-petroleo-bancafarra-de-contratacoes-em-municipios/ (Acesso em 29.10.2010). 


\section{Considerações Finais}

O marco regulatório do setor de petróleo, inaugurado em 1997 a partir da promulgação da Lei 9478/97, introduziu importantes modificações na distribuição das rendas do petróleo no Brasil e ampliou as possibilidades de seu uso na área social. Como resultado desta reforma, o volume destas receitas em poder de um subconjunto específico de municípios brasileiros cresceu substancialmente. Assim, o objetivo deste trabalho foi verificar se estas rendas expressivas permitiram um desenvolvimento social diferenciado para as cidades contempladas. A descoberta do pré-sal e as consequentes perspectivas de ampliação considerável nas rendas do petróleo à disposição do poder público, tornam mais relevantes esta preocupação, sobretudo quando se apresentam propostas de reorganização radical das regras de distribuição, nos moldes da Emenda Ibsen.

Os resultados obtidos sugerem que os indicadores sociais de Saúde e de Educação dos municípios com abundância de recursos de petróleo não responderam de forma significativamente diferente dos municípios que não receberam tais recursos. Já o indicador de emprego e renda formal respondeu negativamente à dependência relativa de recursos do petróleo, de modo que quanto maior a relação royalties-receita corrente, menor o IFDM relativo ao componente Emprego\&Renda. Trata-se de um indício de possível informalização das relações de trabalho nos municípios mais dependentes, corroborando preocupações quanto a estratagemas de contratação que permitam superar as restrições da lei.

Vale ressaltar, também, que estes resultados corroboram as evidências dos estudos publicados até agora, segundo os quais a evolução social dos indicadores de localidades altamente beneficiadas não foi significativamente diferente das não beneficiadas. As conclusões deste estudo também lançam sérias dúvidas sobre o modelo atual de apropriação das rendas do petróleo por municípios produtores. Verifica-se que os municípios contemplados pelas regras definidas no marco regulatório de 1997 não lograram avanços diferenciados em seus indicadores sociais, quando comparados às localidades não produtoras e não confrontantes. A estrutura de incentivos para o uso dos recursos do petróleo determinada pela Lei do Petróleo não parece adequada para fomentar o desenvolvimento social, de modo que a revisão das regras de distribuição destas rendas - na esteira da revisão do marco regulatório do présal - deve fazer parte da agenda política no futuro próximo.

Diversas extensões são possíveis a partir deste trabalho. Em particular, o uso de outros indicadores sociais resultantes do Censo de 2010 poderia trazer maiores informações sobre o mercado de trabalho e sobre investimentos em infraestrutura, não disponíveis nos indicadores da FIRJAN. 


\section{Referências}

BREGMAN, D. Formação, distribuição e aplicação de royalties de recursos naturais: o caso do petróleo no Brasil. Universidade Federal do Rio de Janeiro (Dissertação de Mestrado). Rio de Janeiro, 2007.

CASELLI, F.; MiCHAELS, G. Do oil windfalls improve living standards? Evidence from Brazil. NBER Working paper, 15550, 2009.

COSTA NOVA, L. Análise do impacto social de receitas provenientes de royalties do petróleo em municípios do estado da Bahia. Universidade de Brasília (Dissertação de Mestrado). Brasília, 2005.

DASGUPTA, P.; HEAL, G.M. The optimal depletion of exhaustible resources. Review of Economic Studies, Symposium, 1974, 3-28.

DAVIS, G. A.; TILTON, J.E. The resource curse. Natural Resources Forum 29, 2005, 233-242.

FIRJAN, 2010. Índice Firjan de Desenvolvimento Municipal. Notas metodológicas. Disponível em http://www.firjan.org.br/data/pages/2C908CE9215B0DC401 2164980B735B53.htm acesso em 28 de outubro de 2010).

HARTWICK, J.M. Intergenerational equity and the investing of rents from exhaustible resources. American Economic Review 67, nº 5, dez., /1977, 972-974.

HOTELLING, H. The economics of exhaustible resources. Journal of Political Economy, Abr., 1931, pp.137-175.

LEAL, J.A.A; SERRA, R.V. Notas sobre os fundamentos econômicos da distribuição espacial dos royalties petrolíferos no Brasil. Anais do XXX Encontro Nacional de Economia (ANPEC). Nova Friburgo, Rio de Janeiro, 2002.

MEHLUM, H., MOENE, K., TORVIK, R. Institutions and the resource curse. Economic Journal 116, 2006, 1-20.

NAVARRO, C.A.S. Royalties do petróleo: estudo do caso de Campos dos Goytacazes. Universidade Cândido Mendes (Dissertação de Mestrado). Campos, 2003.

POSTALI, F.A.S. Renda mineral, divisão de riscos e benefícios governamentais na exploração de petróleo no Brasil. Rio de Janeiro: BNDES, 2002.

POSTALI, F.A.S. Petroleum royalties and regional development in Brazil: the economic growth of recipient towns. Resources Policy, vol. 34, 2009, 205-213.

QUINTELLA, S. F. Os royalties de petróleo e a economia do estado do Rio de Janeiro. TCE-RJ. Rio de Janeiro, 2000.

RICARDO, D., 1817, On the principles of political economy and taxation. Col. Os Economistas. Nova Cultural, São Paulo, 1996.

SOLLOW, R.M. Intergenerational equity and exhaustible resources. Review of Economic Studies. Symposium,1974, 29-45.

SACHS, J.; WARNER, A. The curse of natural resources. European Economic Review, vol. 45, 2001, pp. 827-838. 
SERRA, R.V. Desdobramento espacial da exploração e produção de petróleo no Brasil: em busca de um nexo para a distribuição dos royalties entre os Municípios. Belo Horizonte: X ENANPUR, 2003.

SERRA, R. V. O sequestro das rendas petrolíferas pelo poder local: a gênese das quase sortudas regiões produtoras. Revista Brasileira de Estudos Urbanos e Regionais, v. 9, 2007, p. 101-114.

WOOLDRIDGE, J. Econometric analysis of cross section and panel data. Cambridge and London: MIT Press, 2002. 